\title{
Few Layer Reduced Graphene Oxide: Evaluation of the Best Experimental Conditions for Easy Production
}

Giovani Pavoski ${ }^{a}$, Thuany Maraschin ${ }^{b}$, Fabiana de Carvalho Fim ${ }^{a, c}$, Naira Maria Balzarettid,

Griselda Barrera Galland ${ }^{a}$, Cássio Stein Moura ${ }^{e}$, Nara Regina de Souza Basso ${ }^{b *}$

${ }^{a}$ Instituto de Quimica, Universidade Federal do Rio Grande do Sul - UFRGS, Av. Bento Gonçalves, 9500, 91570-970, Porto Alegre, RS, Brazil

${ }^{b}$ Faculdade de Quimica, Pontificia Universidade Católica do Rio Grande do Sul-PUCRS, Av. Ipiranga, 6681, 90619-900, Porto Alegre, RS, Brazil

${ }^{c}$ Centro de Tecnologia, Universidade Federal da Paraíba - UFPB, Cidade Universitária, s/n, 58051900, João Pessoa, PB, Brazil

${ }^{d}$ Instituto de Física, Universidade Federal do Rio Grande do Sul-UFRGS, Av. Bento Gonçalves, 9500, 91570-970, Porto Alegre, RS, Brazil

${ }^{e}$ Faculdade de Física, Pontifícia Universidade Católica do Rio Grande do Sul-PUCRS, Av. Ipiranga, 6681, 90619-900, Porto Alegre, RS, Brazil

Received: September 5, 2015; Revised: July 14, 2016; Accepted: November 3, 2016

This work aimed to produce graphene oxide with few graphene layers, a low number of defects, good conductivity and reasonable amount of oxygen, adequate for use as filler in polymeric composites. Two starting materials were evaluated: expanded graphite and graphite flakes. The method of oxidation used was the Staudenmaier one, which was tested over different lengths of time. No appreciable differences were found among the oxidation times and so the lowest oxidation time $(24 \mathrm{~h})$ was chosen as the most adequate. An investigation was also conducted into suitable temperatures for the reduction of graphite oxide. A temperature of $1000^{\circ} \mathrm{C}$ gave the best results, allowing a good quality material with few defects to be obtained. The reduction was also evaluated under inert and normal atmosphere. The best results were obtained when the least modified material, e. g., graphite flakes, was used as a starting material, oxidized for $24 \mathrm{~h}$ and reduced at $1000{ }^{\circ} \mathrm{C}$ for $30 \mathrm{~s}$ in a quartz ampoule under a normal atmosphere.

Keywords: Graphene oxide, few layer graphene, graphite, graphene

\section{Introduction}

Research on new materials has grown exponentially in recent decades due to the requirements of manufacturers in industry and a plethora of new uses, even in social life. Graphene - a single sheet of carbon atoms organized in a planar bi-dimensional network-is part of a special class of nanofillers with the potential to be used in composites. Graphene, or few layer graphene, can be obtained from graphite (stacked layers of graphene), a low-cost starting material that is found in nature as flakes or a powder with diverse particle sizes. The three largest producers of graphite are China, India and Brazil ${ }^{1}$. Andre Geim and Konstantin Novoselov made an outstanding contribution to the study of graphene's properties and received the Nobel Prize of Physics in 2010 for their innovative experiments ${ }^{2,3}$. They discovered that graphene is 200 times stronger than steel and conducts electricity at room temperature faster than any other known material. It is also highly transparent (97.3\%) and extremely lightweight. Due to these remarkable properties, a large variety of applications seems possible, including the creation of new materials and

*e-mail: nrbass@pucrs.br innovative electronic products ${ }^{4}$. The properties of graphene are very dependent on its structure and therefore it is of great importance investigating methodologies for producing large quantities of single layer graphene. A structured material with a little number of layers of graphene is acceptable as well. In any case, for nanotechnology applications a little amount of defects is mandatory.

The routes to producing graphene include bottom-up and top-down processes. The bottom-up process is related to the synthesis of the material, while the top-down process refers to graphite exfoliation and it is performed until the desired number of graphene layers is achieved ${ }^{5}$. Chemical and mechanical exfoliation of graphite are the only possible methods for obtaining graphene in large quantities and at a low $\cos ^{6}{ }^{6}$. Chemical exfoliation promotes the oxidation of graphite through the introduction of functional groups such as hydroxyl, carbonyl, and epoxide. These groups decrease the interactions between the graphene layers, resulting in an increase of the interlayer distance. The larger space between the graphene sheets helps in carrying out exfoliation, leading to the formation of monolayer or few layers graphene oxide (GO). Electrical properties are influenced by the degree of oxidation and by the surface chemistry of the GO powders? 
Some authors compared the most commonly used oxidation processes, e. g., the Staudenmaier ${ }^{10}$, Hofmann ${ }^{11}$ and Hummers ${ }^{12}$ methods, and showed that the Staudenmaier method produces thermally reduced graphene with the lowest proportion of defects. A comparison of the electrochemical performance of the graphene samples obtained from each of these three oxidation methods and a reduction at $1000^{\circ} \mathrm{C}$ showed that the sample prepared using the Hummers method presented higher heterogeneous transfer rates and lower overpotentials compared with the samples obtained via the other two methods. These data indicate that the preparation method has a dramatic influence on the properties of graphene $^{13}$. Some studies have modified the Staudenmaier process by experimenting with the oxidation time (between 1 and 7 days) and the $\mathrm{HNO}_{3}: \mathrm{H}_{2} \mathrm{SO}_{4}$ acids ratio (1:2 and 1:3), with the aim of obtaining graphene oxide with optimum interlayer spacing. It was found that the optimal conditions were obtained with $\mathrm{HNO}_{3}: \mathrm{H}_{2} \mathrm{SO}_{4}$ at a $1: 3$ volume ratio after $96 \mathrm{~h}$ of oxidation. The interlayer distances could be increased from $3.55 \AA$ of the original graphite to $9.13 \AA \AA$ in modified Staudenmaier method ${ }^{12}$. However, the required reaction time to achieve the appropriate level of intercalation and oxidation also depends on the starting flake size ${ }^{15}$. Aksay et $\mathrm{al}^{16}$. found that $96 \mathrm{~h}$ of oxidation reaction was enough to completely oxidize $45 \mu \mathrm{m}$ flakes but insufficient for 400 $\mu \mathrm{m}$ flakes. Oxygen can be eliminated partially through the thermal or chemical reduction of $\mathrm{GO}^{17}$, resulting in reduced graphene oxide. However, it must be considered that the reduced GO may present defects in the crystalline network that can affect the graphene's electrical properties negatively ${ }^{18}$. Accordingly, intensive research into improving the methodologies for reducing GO and restoring the conductive network is being undertaken ${ }^{19}$. Existing studies have looked at thermal reduction at high temperatures (1050 $\left.{ }^{\circ} \mathrm{C}\right)^{16,20}$ and at low temperatures $\left(125-240{ }^{\circ} \mathrm{C}\right){ }^{21,22}$, whilst other works have examined the influence of the amount of carbon and oxygen on conductivity after thermal reductions at $900^{\circ} \mathrm{C}$ and $1100^{\circ} \mathrm{C}^{23}$. Many of these studies are difficult to compare because they use different oxidation methods and reduction conditions. Diffusion coefficient calculations suggest that there is a critical temperature of $550{ }^{\circ} \mathrm{C}$ that must be exceeded for exfoliation to occur ${ }^{23}$. The present work aims to develop a methodology for obtaining large quantities of few layer reduced graphene oxide from graphite at a low cost, while presenting good quality and a reasonable amount of oxygen, which could be used as nanofiller for composites $^{24}$. Since the starting material plays an important role, we decided to compare two materials: graphite flakes (FK) and expanded graphite (EG). The oxidation process used was the Staudenmaier ${ }^{10}$ method. Various reaction times were tested (24, 48, 72 e 96h). Thermal reduction processes at 600,700 , and $1000{ }^{\circ} \mathrm{C}$, in different atmospheres (normal and inert), were also investigated.

\section{Experimental}

\subsection{Materials}

All materials were used as received. Expanded graphite Micrograph HC11 (EG) with an average size of around 50 $\mu \mathrm{m}$ and Graflake 9950 (FK) with a size of around $150 \mu \mathrm{m}$ were provided by Nacional de Grafite Ltda. Brazil. Sulfuric acid, nitric acid, hydrochloric acid, and potassium chlorate were purchased from Merck Chemical Company (Brazil).

\subsection{Graphite Oxide Synthesis}

The graphite oxide (GO) was synthesized from EG and FK powders using the Staudenmaier method ${ }^{10}$. An acidic mixture of $\mathrm{H}_{2} \mathrm{SO}_{4}(160 \mathrm{~mL})$ and $\mathrm{HNO}_{3}(90 \mathrm{~mL})$ was stirred in a round-bottomed flask placed in an ice bath for $1 \mathrm{~h}$. After this time, $10 \mathrm{~g}$ of graphite (EG or FK) were added and stirred for $20 \mathrm{~min}$. Subsequently, $110 \mathrm{~g}$ of $\mathrm{KClO}_{3}$ was added slowly over 15 mins, with the temperature being controlled to prevent a rise above $35^{\circ} \mathrm{C}$. Small amounts of $\mathrm{KCl}$ were added to minimize the risk of explosion, which can be caused by the $\mathrm{ClO}_{2}$ gas. The reaction was allowed to proceed over different intervals of time (24, 48, 72 e 96h). On completion of the reaction, an aqueous $\mathrm{HCl}$ solution $(10 \% \mathrm{v} / \mathrm{v})$ was added to the suspension in order to remove sulfate ions. Afterwards, washing with deionized water and centrifuging (4500 rpm) were carried out several times in order to reach $\mathrm{pH} 3$. The resulting suspension was placed in a dialysis membrane until the $\mathrm{pH}$ of solution was 5 , and then the resulting brown suspension was dried in an oven at $150^{\circ} \mathrm{C}$. The graphite oxide was then heated at 600,700 , and $1000^{\circ} \mathrm{C}$ for $30 \mathrm{~s}$ in an oven, using a closed quartz ampoule with either a normal or an inert atmosphere of argon.

\subsection{Characterization}

$\mathrm{X}$-ray diffraction (XRD) measurements for the powdered samples were performed on a diffractometer (Rigaku, DMAX 2200) equipped with a $\mathrm{Cu}$ tube $(\lambda=0.15418 \mathrm{~nm})$ and a secondary monochromator. The goniometer used was a Siemens D500 and the detector was the scintillator (NaI and Tl). XRD samples were prepared by coating the sample holder with a uniform layer of the powdered samples at room temperature. From the XRD parameters, the interlayer distances $\left(\mathrm{d}_{002}\right)$ in the graphene were estimated using Bragg's Law ${ }^{25}$.

The grain size (C) was calculated using the Scherrer equation $^{26,27}$ :

$$
C=\frac{0.9 \lambda}{\beta \cos \theta}
$$

Here, $\beta$ is the line width at half height in the radians and $\theta$ is the diffraction angle. 
The number of graphene layers was calculated by dividing the crystal size $(C)$ by the interlayer distance $(d)$ added to the thickness of one graphene sheet $(0.1 \mathrm{~nm})$.

Raman analyses were performed at room temperature using an Olympus microscope and an iH320 Jobin Yvon Spectrometer with a CCD (charged coupled device) detector, cooled by liquid nitrogen. The excitation source was a $10 \mathrm{~mW}$ $\mathrm{HeNe}$ laser $(632.8 \mathrm{~nm})$ and the acquisition time was $20 \mathrm{~s}$.

$\mathrm{GO}$ samples were analyzed at $25^{\circ} \mathrm{C}$ as pellets diluted in $\mathrm{KBr}$ by transmission FT-IR spectroscopy, using a Varian FTIR spectrophotometer (640-IR), which accumulated 32 scans at a $4 \mathrm{~cm}^{-1}$ resolution.

The fractions of $\mathrm{C}, \mathrm{H}$, and $\mathrm{N}$ in the graphite samples were analyzed using a Perkin-Elmer MCHNSO/2400 analyzer. A sample mass of $2 \mathrm{mg}$ was employed in each analysis.

Scanning Electron Microscopy (SEM) was performed with a Phillips microscope (model XL30) operating at 20 $\mathrm{kV}$, using aluminum stubs and gold metallization.

Transmission Electron Microscopy (TEM) images of the reduced graphene oxide were obtained using a JEOL 2010 transmission electron microscope operated at $200 \mathrm{kV}$. All the samples were prepared by depositing an acetone suspension drop on a copper grid (300 mesh) covered with amorphous carbon.

Electrical impedance spectroscopy was performed to measure the electrical conductivity of the samples. A sine wave with $1.0 \mathrm{Vpp}$ was applied to the sample and the frequency was varied from 1 to $10^{6} \mathrm{~Hz}$. The current and the potential differences between the samples' faces were measured. The phase difference between the voltage and current in the sample allows the determination of the real and imaginary parts of electrical impedance. The real part is associated with conductivity. A numerical fitting algorithm was applied to the data, which provided the conductivity values.

\section{Results and Discussion}

In order to evaluate the need for pre-treatment in the oxidation process, two different types of graphite were employed as starting materials: expanded graphite (EG) and graphite flake (FK). Figure 1 shows the XRD patterns of $\mathrm{EG}$ and $\mathrm{FK}$. It is possible to observe the interlayer spacing along the c-axis- $\left(\mathrm{d}_{002}\right)$ at $26.5^{\circ}$ and $\left(\mathrm{d}_{004}\right)$ at $\sim 55^{\circ}$ - as sharp peaks for FK. In Table 1, it can be seen that both graphites present a very close spacing between the graphene layers but the crystal size of EG is smaller, which indicates a smaller graphene stack. The inexistence of peak at $55^{\circ}$ in EG suggests it has a lower aspect ratio than FK.

Raman spectroscopy is commonly considered to be the most important technique in characterizing the structure of graphitic materials ${ }^{28}$. The main Raman features of graphene and graphite are the $\mathrm{G}$ band $\left(\sim 1580 \mathrm{~cm}^{-1}\right)$, the $\mathrm{D}$ band $\left(\sim 1330 \mathrm{~cm}^{-1}\right)$ and the $\mathrm{G}^{\prime}$ band $\left(\sim 2670 \mathrm{~cm}^{-1}\right)$ for an excitation wavelength of $632.8 \mathrm{~nm}$. The $\mathrm{G}$ band originates from the

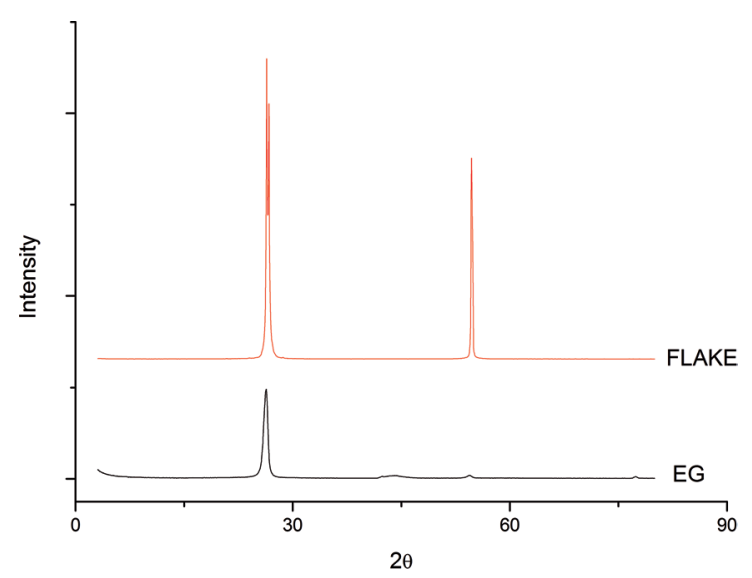

Figure 1: XRD patterns of starting graphite materials

Table 1: Data obtained from the XRD patterns of EG and FK

\begin{tabular}{lccc}
\hline Sample & $2 \theta\left(^{\circ}\right)$ & $\mathrm{d}_{002}(\mathrm{~nm})$ & $\mathrm{C}(\mathrm{nm})$ \\
\hline EG & 26.52 & 0.3390 & 14 \\
Flake & 26.55 & 0.3356 & 17 \\
\hline
\end{tabular}

in-plane vibration of $\mathrm{sp}^{2}$ carbon atoms. The $\mathrm{D}$ band is related to crystal disorder due to $\mathrm{sp}^{3}$ defects in the $\mathrm{sp}^{2}$ lattice and the $\mathrm{G}^{\prime}$ band is an overtone of the disorder-induced D-band. For single layer graphene, the $\mathrm{G}^{\prime}$ band appears as a sharp and symmetrical peak, whereas it becomes broader when the thickness increases (for example, in few layer graphene) ${ }^{29}$. Figure 2 shows the Raman spectra of the two types of graphitic structures used in this work, namely, FK and EG. It can be observed that both structures present defects (peak D at 1330 $\mathrm{cm}^{-1}$ ). The larger and less intense $\mathrm{G}^{\prime}$ band suggests that the EG sheets contain more defects compared to the FK sheets.

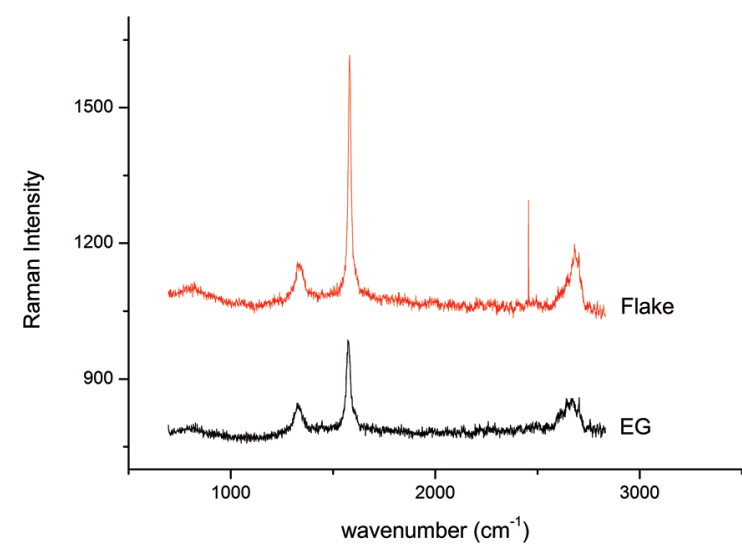

Figure 2: Raman spectra of starting graphite materials

\subsection{Reduced graphene oxide obtained from expanded graphite}

The strong oxidation of EG using Staudenmaier methodology over $96 \mathrm{~h}$ resulted in graphite oxide (GO96h). The formation of GO is indicated by the increase of the interlayer spacing along the $\mathrm{c}$-axis $\left(\mathrm{d}_{002}\right)$ due to the insertion of 
various oxygen-containing functional groups in the graphite structure $^{2}$. Figure 3 shows the XRD patterns of GO prepared from $\mathrm{EG}$ oxidation.

The data listed in Table 2 refers to the parameters of $\mathrm{XRD}$ and the percentage of carbon and oxygen obtained from $\mathrm{CHN}$ analysis for $\mathrm{EG}, \mathrm{GO} 96 \mathrm{~h}$ and reduced $\mathrm{GO}$ at different temperatures $\left(600,700\right.$ or $\left.1000^{\circ} \mathrm{C}\right)$.

The formation of GO96h is confirmed by the absence of the (002) diffraction line at $26.52^{\circ}(d$-space $=0.33 \mathrm{~nm})$ that is typical of EG and the appearance of the diffraction peak at $11.23^{\circ}(\mathrm{d}$-space $=0.78 \mathrm{~nm})($ Figure 3$)$. Moreover, a marked decrease in the crystal size $(8 \mathrm{~nm})$ compared to the starting graphite $(14 \mathrm{~nm})$ was also observed. During the oxidation process, the insertion of various oxygen-containing functional groups that are bonded to the edges of basal planes of the graphite structure occurs. The ratio between the carbon and oxygen obtained by $\mathrm{CHN}$ analysis shows that oxidation was almost complete after $96 \mathrm{~h}(\mathrm{C} / \mathrm{O} \cong 1)$. A high percentage of oxygen is very important for the expansion and exfoliation of graphene sheets, since the percentage represents the number of molecules that will decompose in gases during thermal treatment ${ }^{15}$. Aksay et al. ${ }^{16}$ determined the composition of gases that cause the rapid expansion of graphite - namely, $\mathrm{CO}_{2}$ and $\mathrm{H}_{2} \mathrm{O}$ - demonstrating they originate from the exothermic decomposition of the hydroxyl and epoxide groups of GO.

When EG is oxidized to become GO, the insertion of oxygen functional groups decreases electrical conductivity due to a disruption in the planar $\mathrm{sp}^{2}$ carbon sheets because of the introduction of $\mathrm{sp}^{3}$-hybridized carbons ${ }^{5}$. In order to restore the $\pi$-network, the GO was submitted to thermal reduction and the influence of the reduction temperature on the reduced graphene oxide was evaluated. The thermal treatments were carried out in an oven using a quartz ampoule.

Figure 4 shows the XRD patterns of GO96h samples that were heated at 600,700 , and $1000{ }^{\circ} \mathrm{C}$ (GO96h6, GO96h7, and GO96h10, respectively). All the reduced GO samples showed a broad peak that corresponded to $0.78 \mathrm{~nm}$ GO interlayer separation, indicating that the reduction process was not complete. A very large peak at $2 \theta \cong 26.5^{\circ}$ reappeared for the samples reduced at 600 and $700^{\circ} \mathrm{C}$, showing that the graphitic structure was partially restored. However, the peak broadens even more for higher temperatures, presumably due to the corrugated structure of the reduced GO sheets. Although the absence of the (002) diffraction line at $2 \theta=$ $26.5^{\circ}$ in the XRD spectrum of GO96h10 suggests that all stacking was lost, it may also indicate that any remaining stacking was disordered $^{16}$.

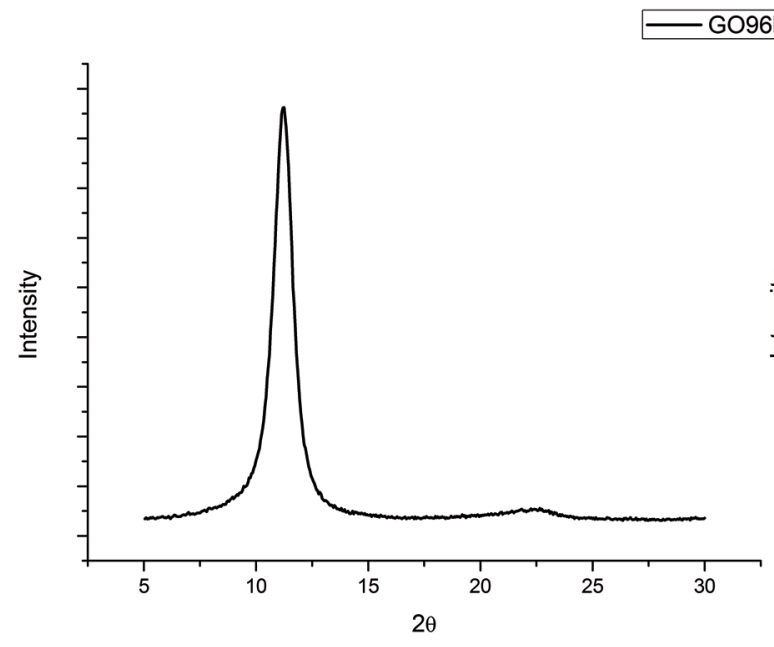

(a)

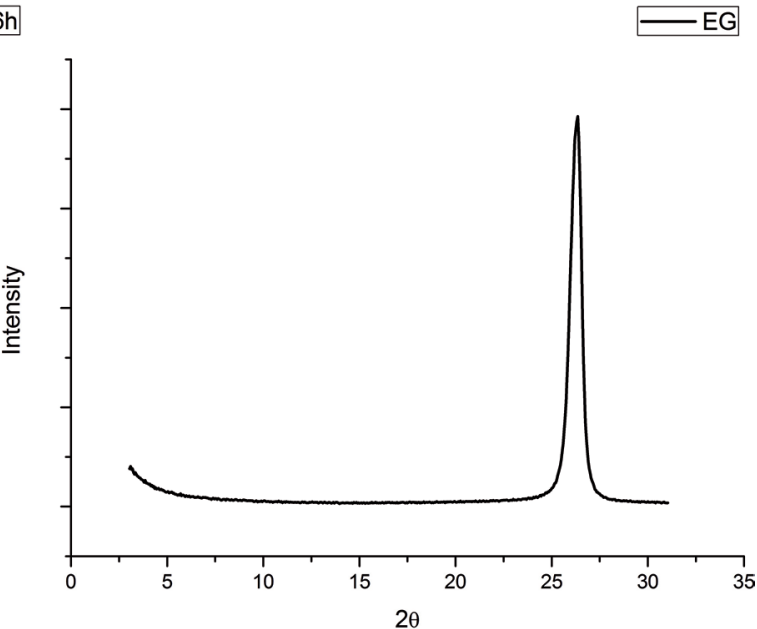

(b)

Figure 3: XRD patterns of GO96h (a) and EG (b)

Table 2: Data obtained from the XRD patterns and CHN of EG, GO96h and reduced GO96h at different temperatures.

\begin{tabular}{|c|c|c|c|c|c|c|c|c|}
\hline \multirow{2}{*}{ Sample } & \multicolumn{2}{|c|}{$2 \theta\left({ }^{\circ}\right)$} & \multicolumn{2}{|c|}{$\mathrm{d}_{002}(\mathrm{~nm})$} & \multicolumn{2}{|c|}{ Grain size $C(\mathrm{~nm})$} & \multicolumn{2}{|c|}{$\mathrm{CHN}$} \\
\hline & & & & & & & $\% \mathrm{C}$ & $\% \mathrm{O}$ \\
\hline EG & & 26.52 & & 0.33 & & 14 & 97.5 & 2.4 \\
\hline GO96h & 11.23 & & 0.78 & & 8 & & 49.9 & 47.8 \\
\hline *GO96h6 & 10.74 & 24.14 & 0.82 & 0.37 & 9 & 3 & 73.3 & 25.7 \\
\hline GO96h7 & 10.95 & 24.36 & 0.81 & 0.37 & 8 & 3 & 74.1 & 24.7 \\
\hline GO96h10 & 10.79 & & 0.82 & & 11 & & 80.2 & 19.0 \\
\hline
\end{tabular}

*GO96h6: correspond to GO $96 \mathrm{~h}$ that was reduced at $600^{\circ} \mathrm{C}$. The same nomenclature was used for the other temperatures. 


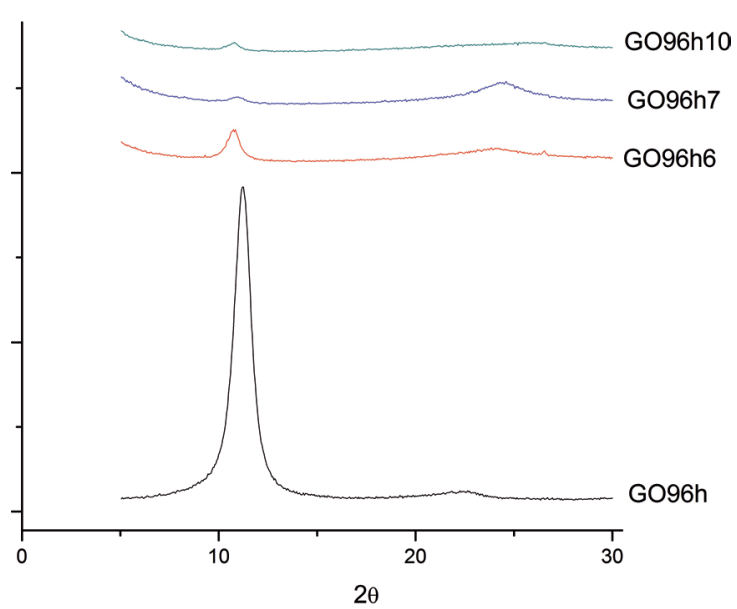

Figure 4: XRD patterns of GO and reduced GO96h at different temperatures

According to Table 2, the data from the elemental analysis is consistent with the results obtained from XRD. An increase in the $\mathrm{C} / \mathrm{O}$ ratios in the reduced samples can be seen when compared with the starting GO96h (1.0), evidencing a successful thermal reduction. Although oxygen functional groups were still retained in the structure at all the evaluated temperatures, it was observed that the $\mathrm{C} / \mathrm{O}$ ratio increased with increasing of the reduction temperature.

The oxygen-functionalized graphene sheets present opportunities for several applications, such as the preparation of composites in which those groups can have an important role in the interaction between graphene sheets and the polymeric matrix ${ }^{7}$. Covalent functionalization of graphene with the polymer can improve the dispersion in nanocomposites ${ }^{8}$. For example, some hydroxyl functional groups on the surface of graphene were used to support the catalyst system, in the in situ polymerization of ethylene, improving the graphite exfoliation in the polymeric matrix and consequently the nanocomposite properties. Table 2 also shows that the differences in the amount of oxygen in the samples reduced at temperatures of 600 and $700^{\circ} \mathrm{C}$ are not significant. Even at the highest reduction temperature, $1000^{\circ} \mathrm{C}$, roughly $19 \%$ of oxygen atoms remained.

Figure 5 shows the Raman spectra for thermally reduced GO96h. According to the Raman spectra, part of the $\mathrm{sp}^{2}$ carbon network was restored, though with many defects.

Considering that $96 \mathrm{~h}$ of oxidation reaction seems to damage the graphitic structure of EG excessively, shorter reaction times $(24,48$, and $72 \mathrm{~h})$ were evaluated with the purpose of reducing the defects in the graphene sheets obtained after thermal reduction. However, after thermal reduction of the GO samples at $1000^{\circ} \mathrm{C}$, the Raman spectra showed no significant differences, when compared with using an oxidation time of $96 \mathrm{~h}$ (see Figure 6).

In fact, these Raman spectra show that a shorter EG oxidation time neither reduces the prevalence of defects, nor affects the stacking ordering. The $\mathrm{sp}^{2}$ structure, therefore, is not recovered completely during the reduction process.

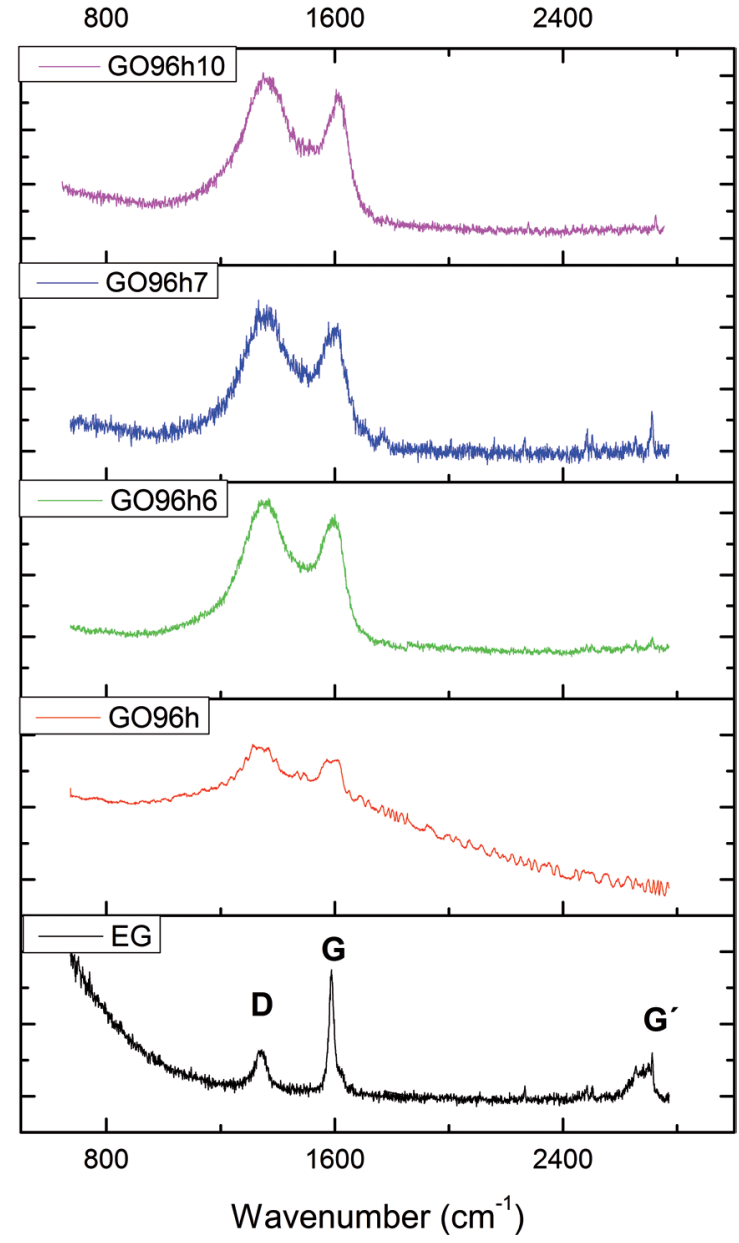

Figure 5: Raman spectra of EG, GO96h and reduced GO at 600, 700 and $1000{ }^{\circ} \mathrm{C}$

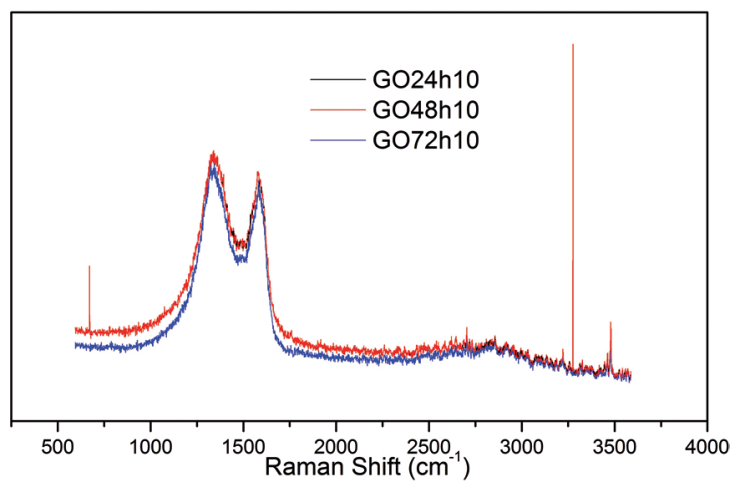

Figure 6: Raman spectra of EG oxidized over different reaction times $(24,48$, and $72 \mathrm{~h})$ and reduced at $1000{ }^{\circ} \mathrm{C}$

Considering the EG exfoliation, it is possible to conclude that a high degree of oxidation was obtained even after the lowest period of oxidation ( $24 \mathrm{~h}$ ), giving $\mathrm{C} / \mathrm{O}$ ratios close to 1 , reducing the crystal size, and increasing interlayer distances. However, even at the highest temperature $\left(1000^{\circ} \mathrm{C}\right)$, the reduction was insufficient for recuperating the $\mathrm{sp}^{2}$ network, thus leading to the production of few layer reduced graphene oxide with many defects. 


\subsection{Reduced graphene oxide from graphite flake}

Using the same experimental approach as for EG, GO samples were prepared from graphite flakes (FK). Different oxidation times $(96,72,48$, and $24 \mathrm{~h}$ ) were evaluated. Figure 7 shows some of the typical XRD patterns for GO obtained from FK.

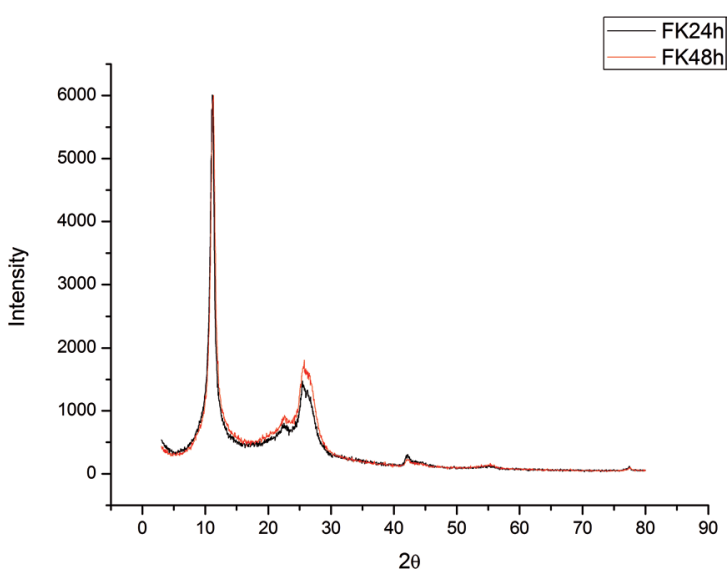

Figure 7: XRD patterns of FK oxidized over 24 (FK24h) and 48 h (FK48h)

In contrast to what was observed with EG, FK was only partially oxidized over all the evaluated reaction times. The existence of fewer defects in the FK structure relative to EG may affect the oxidative breakup and a time longer than 96 hours may be required for complete oxidation to occur ${ }^{16}$. Elemental analysis was performed on the graphene oxides in order to evaluate the degree of oxidation (Table 3).

Table 3: Elemental analysis of GO obtained from different lengths of oxidation time.

\begin{tabular}{lcccc}
\hline Sample & $\% \mathrm{C}$ & $\% \mathrm{H}$ & $\% \mathrm{~N}$ & $\% \mathrm{O}$ \\
\hline FK24h & 64.6 & 2.0 & 0.7 & 32.6 \\
FK48h & 62.3 & 2.1 & 0.7 & 34.8 \\
FK72h & 68.8 & 1.6 & 0.6 & 28.9 \\
FK96h & 68.0 & 1.6 & 0.7 & 29.6 \\
\hline
\end{tabular}

According to Table 3, the degree of oxidation was practically independent of the reaction time. It is possible to conclude, therefore, that a 24 -hour period of oxidation is long enough to prepare oxidized graphite flake with about $30 \%$ oxygen.

The FTIR spectrum of graphite oxide FK24h (presented in Figure 8) shows the stretching vibrations of $\mathrm{O}-\mathrm{H}$ and $\mathrm{C}-\mathrm{O}$ at 3398 and $1083 \mathrm{~cm}^{-1}$ respectively. The stretching $\mathrm{C}=\mathrm{C}$ double bonds of the condensed rings of graphene appear at $1621 \mathrm{~cm}^{-1}$. This band has a shoulder at around $1700 \mathrm{~cm}^{-1}$ that can be attributed to the presence of some carbonyl groups $(\mathrm{C}=\mathrm{O})$ in small amounts. The presence of some stretching vibrations from $\mathrm{C}-\mathrm{H}$ bonds $\left(\mathrm{C} \mathrm{sp}^{3}\right)$ is also evident between 2800 and $3000 \mathrm{~cm}^{-1}$.

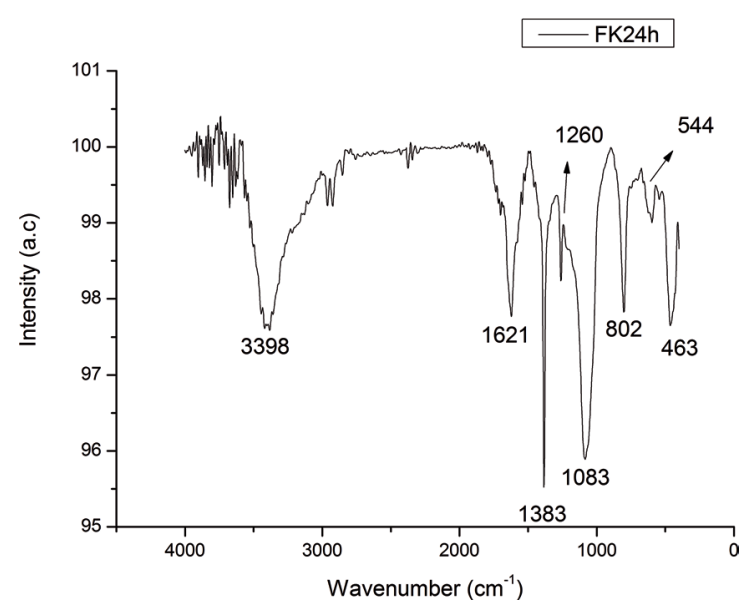

Figure 8: Transmission FTIR spectrum for FK oxidized over $24 \mathrm{~h}$ (FK24h), dispersed in $\mathrm{KBr}$

The thermal reduction of the flake oxidized over $24 \mathrm{~h}$ was tested at 600,700 , and $1000{ }^{\circ} \mathrm{C}$. A very simple method of reduction was evaluated using an open quartz capsule placed in the oven. However, this procedure resulted on the loss of the most exfoliated fractions, especially at the highest reduction temperatures. Thus, for the reduction reactions, a closed quartz ampoule was chosen instead, which was tested using normal and inert atmospheres. Figure 9 shows the XRD patterns for the samples obtained after FK was oxidized over $24 \mathrm{~h}$ and reduced at 600,700 , and $1000{ }^{\circ} \mathrm{C}$ in a closed quartz ampoule, both in an inert atmosphere (FK24h6APIN, FK24h7APIN, FK24h10APIN) and a normal atmosphere (FK24h6AP, FK24h7AP, FK24h10AP). Table 4 gives the XRD patterns for the data obtained.

According to Figure 9, the reduction of GO in an inert atmosphere at temperatures of 600 and $700{ }^{\circ} \mathrm{C}$ presents large diffraction peaks, suggesting heterogeneity in the stacking distances. At a reaction temperature of $1000^{\circ} \mathrm{C}$, the peak is thinner, even though the average interlayer distance is the same, namely $0.35 \mathrm{~nm}$, which is higher than in the starting graphite $(0.33 \mathrm{~nm}$ in FK). In all cases, there was significant exfoliation from about 40 graphenes per crystal in FK to 5-11 graphenes per crystal in the reduced graphene oxides. The reduction performed in a closed quartz ampoule in a normal atmosphere was more efficient at a temperature of $1000^{\circ} \mathrm{C}$ because at 600 and $700^{\circ} \mathrm{C}$, there is still a broad diffraction band at $11.29^{\circ}$, which is characteristic of GO. It can thus be seen that the reduction is less efficient at lower temperatures. At a reduction temperature of $1000^{\circ} \mathrm{C}$, the exfoliation is the same in an inert or a normal atmosphere (11 graphenes per crystal).

The Raman spectra in Figure 10 show that the oxidized graphite (FK24h) reduced at $1000^{\circ} \mathrm{C}$ in a normal atmosphere gives the best recuperation of the $\mathrm{sp}^{2}$ network, compared with the sample reduced at lower temperatures or in an inert atmosphere. The ratio between the intensities of the $D$ and $G$ peaks is normally used as a quantitative parameter of defect 


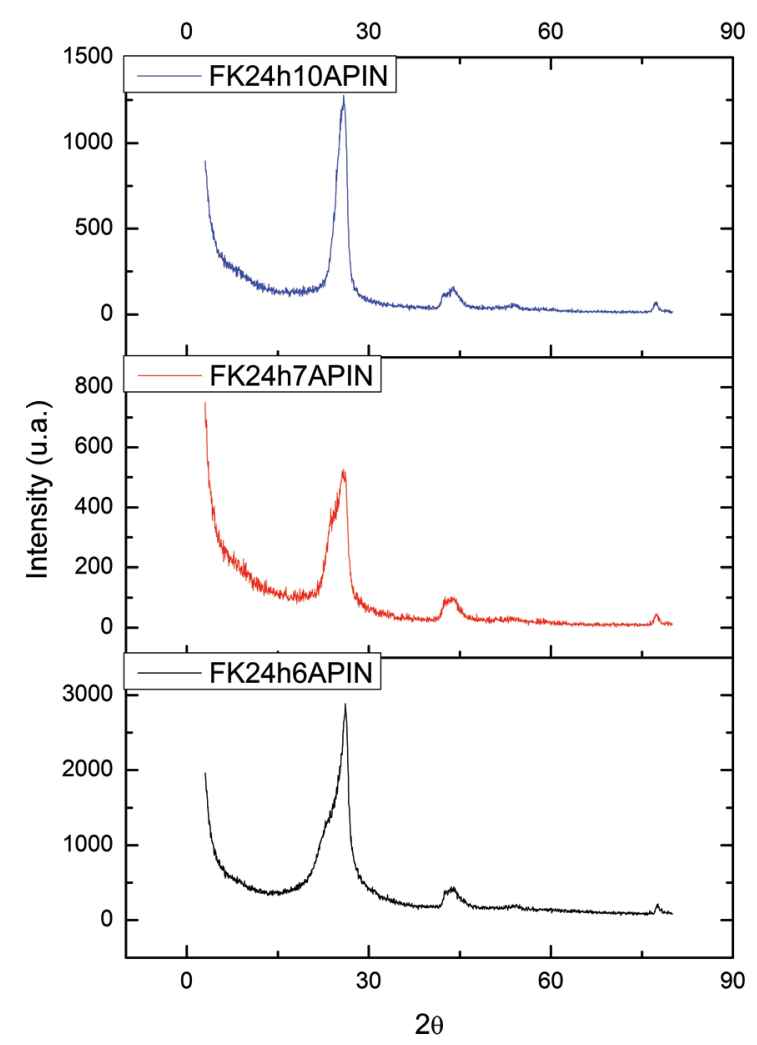

(a)

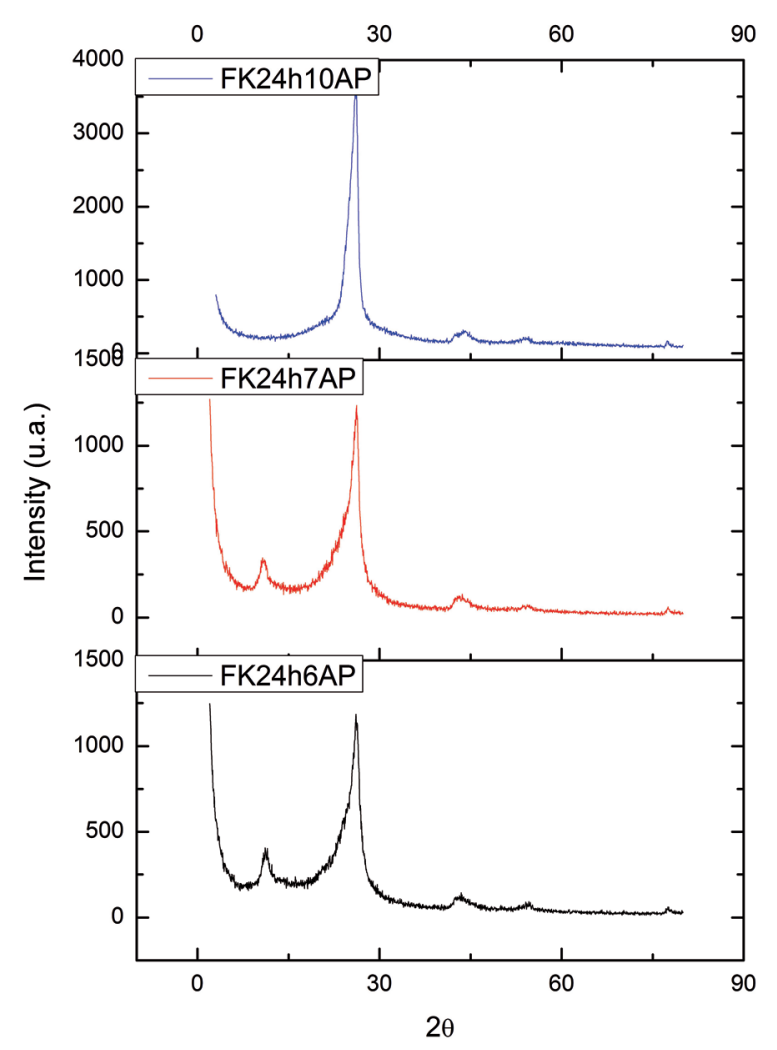

(b)

Figure 9: XRD patterns for GO samples reduced in a closed quartz ampoule in (a) an inert (APIN) and (b) a normal (AP) atmosphere

Table 4: Data obtained from the XRD patterns for reduced GO samples treated in a closed quartz ampoule.

\begin{tabular}{lcccc}
\hline Sample & $2 \theta\left(^{\circ}\right)$ & $\mathrm{d}(\mathrm{nm})$ & $\mathrm{C}(\mathrm{nm})$ & Graphene \# \\
\hline FK & 26.55 & 0.33 & 17 & 40 \\
FK24h6APIN & 25.25 & 0.35 & 2 & 5 \\
FK24h6AP & 25.65 & 0.35 & 3 & 7 \\
FK24h7APIN & 25.08 & 0.35 & 3 & 6 \\
SFK24h7AP & 25.67 & 0.35 & 9 & 20 \\
FK24h10APIN & 25.52 & 0.35 & 5 & 11 \\
FK24h10AP & 25.71 & 0.35 & 5 & 11 \\
\hline
\end{tabular}

prevalence in graphite. In Figure 10 , the $\mathrm{I}_{\mathrm{D}} / \mathrm{I}_{\mathrm{G}}$ ratios for normal and inert atmospheres are 0.8 and 1.1 respectively, confirming the presence of fewer defects in the reduced oxide obtained at $1000^{\circ} \mathrm{C}$ in a normal atmosphere, compared with other samples.

According to the results of the elemental analysis (Table 5), an increase in the reaction temperature from 600 to $1000^{\circ} \mathrm{C}$ raises the $\mathrm{C} / \mathrm{O}$ ratio, as expected. The use of an inert or a normal atmosphere does not have a significant influence on the amount of oxygen that occurs in the reduced graphite. After reduction at the highest temperature $\left(1000^{\circ} \mathrm{C}\right)$, there is still a reasonable amount of oxygen present (13\%), which can be used in compatibility reactions for the preparation of composites. In any case, the amount of oxygen is inferior to that obtained when EG is used as a starting material.

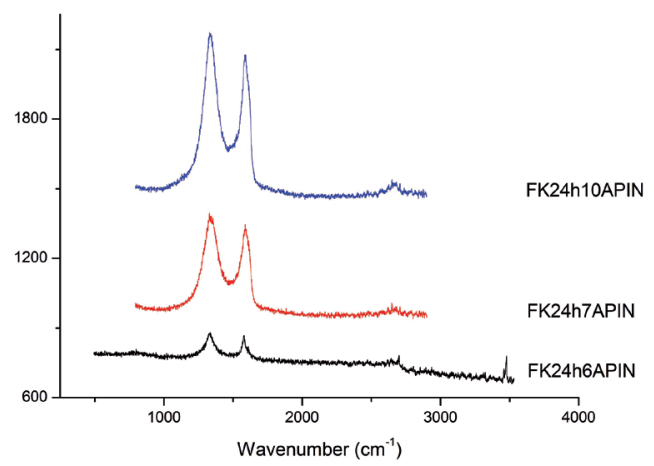

(a)

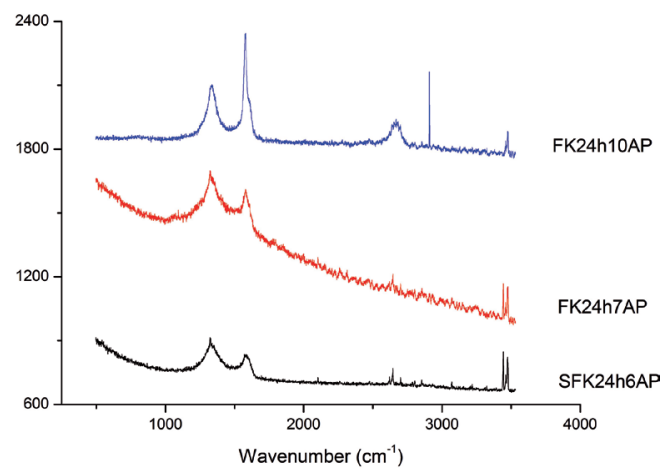

(b)

Figure 10: Raman spectra of GO samples reduced in a quartz ampoule in (a) an inert and (b) a normal atmosphere 
Table 5: Elemental analysis of reduced GO obtained in a closed ampoule.

\begin{tabular}{lll}
\hline Sample & $\% \mathrm{C}$ & $\% \mathrm{O}$ \\
\hline GO & 64.7 & 33.9 \\
FK24h6APIN & 72.3 & 27.0 \\
FK24h7APIN & 85.5 & 14.2 \\
FK24h10APIN & 86.7 & 13.1 \\
FK24h10AP & 86.3 & 13.2 \\
\hline
\end{tabular}

The HRTEM image of the FK24h10AP sample shows a few layer graphene sheet, which indicates that an effective exfoliation of graphite oxide has taken place (Figure 11).

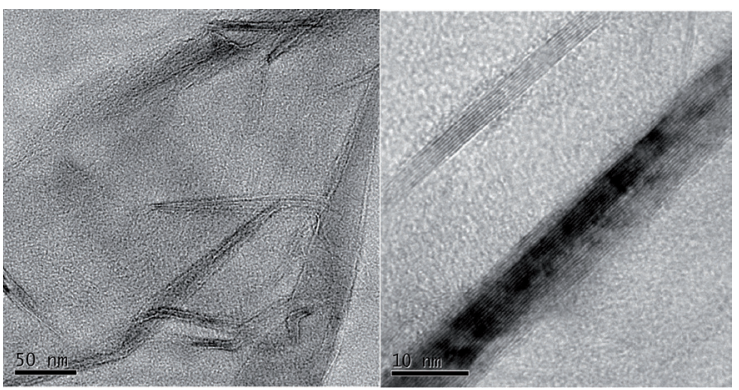

Figure 11: HRTEM micrographic image of oxide graphene oxidized over $24 \mathrm{~h}$ and thermally reduced at $1000^{\circ} \mathrm{C}$ in a closed quartz ampoule in a normal atmosphere.

Table 6 shows the conductivity values for the samples, measured by electrical impedance spectroscopy prior to and after reduction treatment. One can observe that the oxidation of the FK decreased the electric conductivity of sample FK24h slightly; however, the reduction process, independent of the temperature, was very efficient in restoring the $\mathrm{sp}^{2}$ network, which is responsible for conductivity. The oxidation process and the reduction resulted in a material composed of few layer graphene, which is roughly one order of magnitude more conductive than the raw material.

Table 6: Electrical conductivity of raw materials oxidized and reduced graphite.

\begin{tabular}{lc}
\hline Sample & Electrical conductivity $(\mathrm{S} / \mathrm{cm})$ \\
\hline FK & $6.0 \times 10^{-2}$ \\
EG & $3.5 \times 10^{-2}$ \\
FK24h & $1.2 \times 10^{-2}$ \\
FK24h6APIN & $1.6 \times 10^{-1}$ \\
FK 24h7APIN & $2.7 \times 10^{-1}$ \\
FK24h10PIN & $2.7 \times 10^{-1}$ \\
FK24h10AP & $1.7 \times 10^{-1}$ \\
\hline
\end{tabular}

\section{Conclusions}

Using expanded graphite $(50 \mu \mathrm{m}$, crystal size $14 \mathrm{~nm})$ as a starting material to obtain reduced graphite oxide produced few layer graphene with many defects. The raw untreated graphite (flake, $150 \mu \mathrm{m}$, crystal size $17 \mathrm{~nm}$ ) was found to be the starting material most appropriate for producing reduced graphene oxide through the modified Staudenmaier method. Reduced graphene oxide containing roughly $13 \%$ oxygen, a low density of defects and a low number of graphene layers was obtained from oxidation of the graphite flake over a $24 \mathrm{~h}$ period, followed by thermal reduction at $1000{ }^{\circ} \mathrm{C}$ in a quartz ampoule using a normal atmosphere. The use of an inert atmosphere during the reduction process did not improve the structure or electrical properties of the resulting reduced graphene oxide. The electrical conductivity of the few layer graphene obtained was ten times superior to that of the starting graphite.

The few layer graphene material with a low defect density that was obtained is adequate for many applications, such as use in polymeric composites, for example.

\section{Acknowledgments}

The authors would like to thank CNPq, CAPES and FAPERGS for financial support. We also thank Nacional de Grafite Ltda., Brazil for the Micrograph HC11 and Graflake 9950 supply.

\section{References}

1. US Geological Survey. Mineral Commodity Summaries. Washington: US Department of the Interior; 2013. Available from: <http:// minerals.usgs.gov/minerals/pubs/mcs/2013/mcs2013.pdf $>$. Access in: 15/10/2014.

2. Novoselov KS, Geim AK, Morozov SV, Jiang D, Zhang Y, Dubonos $\mathrm{SV}$, et al. Electric field effect in atomically thin carbon films. Science. 2004;306(5696):666-669.

3. The Official Web Site of the Nobel Prize. The Nobel Prize in Physics 2010. Nobelprize.org; 2010. Available from: <http:// www.nobelprize.org/nobel_prizes/physics/laureates/2010/>. Access in: 04/01/2012.

4. Salavagione HJ, Martinez G, Ellis G. Recent Advances in the Covalent Modification of Graphene with Polymers. Macromolecular Rapid Communications. 2011;32(22):1771-1789.

5. Moura CS, Amaral L. Carbon nanotube ropes proposed as particle pipes. Carbon. 2007;45(9):1802-1807.

6. Wu ZS, Ren W, Gao L, Liu B, Jiang C, Cheng HM. Synthesis of high-quality graphene with a pre-determined number of layers. Carbon. 2009;47(2):493-499.

7. Guerrero-Contreras J, Caballero-Briones F. Graphene oxide powders with different oxidation degree, prepared by synthesis variations of the Hummers method. Materials Chemistry and Physics. 2015;153:209-220.

8. Zhang M, Li Y, Su Z, Wei G. Recent advances in the synthesis and applications of graphene-polymer nanocomposites. Polymer Chemistry. 2015;6(34):6107-6124.

9. Pavoski G, Maraschin T, Milani MA, Azambuja DS, Quijada R, Moura CS, et al. Polyethylene/reduced graphite oxide nanocomposites with improved morphology and conductivity. Polymer. 2015;81:79-86. 
10. Staudenmaier L. Verfahren zur Darstellung der Graphitsäure. Berichte der deutschen chemischen Gesellschaft. 1898;31(2):1481-1487.

11. Hofmann U, König EZ. Untersuchungen über Graphitoxyd. Zeitschrift für Anorganische und Allgemeine Chemie. 1937;234(4):331-336.

12. Hummers WS Jr., Offeman RE. Preparation of graphitic oxide. Journal of the American Chemical Society. 1958;80(6):1339.

13. Poh HL, Šaněk F, Ambrosi A, Zhao G, Sofer Z, Pumera M. Graphenes prepared by Staudenmaier, Hofmann and Hummers methods with consequent thermal exfoliation exhibit very different electrochemical properties. Nanoscale. 2012;4(11):3515-3522.

14. Sheshmani S, Fashapoyeh MA. Suitable Chemical Methods for Preparation of Graphene Oxide, Graphene and Surface Functionalized Graphene Nanosheets. Acta Chimica Slovenica. 2013;60(4):813-825.

15. Jang BZ, Zhamu A. Processing of nanographene platelets (NGPs) and NGP nanocomposites: a review. Journal of Materials Science. 2008;43(15):5092-5101.

16. McAllister MJ, Li JL, Adamson DH, Schniepp HC, Abdala AA, Liu J, et al. Single Sheet Functionalized Graphene by Oxidation and Thermal Expansion of Graphite. Chemistry of Materials. 2007;19(18):4396-4404.

17. Schniepp HC, Li J, McAllister MJ, Sai H, Herrera-Alonso M, Adamson DH, et al. A Functionalized Single Graphene Sheets Derived from Splitting Graphite Oxide. The Journal of Physical Chemistry B. 2006;110(17):8535-8539.

18. Stankovich S, Dikin DA, Piner RD, Kohlhaas KA, Kleinhammes A, Jia Y, et al. Synthesis of graphene-based nanosheets via chemical reduction of exfoliated graphite oxide. Carbon. 2007;45(7):1558-1565.

19. Herrera-Alonso M, Abdala AA, McAllister MJ, Aksay IA, Prud'homme RK. Intercalation and Stitching of Graphite Oxide with Diaminoalkanes. Langmuir. 2007;23(21):10644-10649.
20. Becerril HA, Mao J, Liu Z, Stoltenberg RM, Bao Z, Chen Y. Evaluation of Solution Processed Reduced Graphene Oxide Films as Transparent Conductors. ACS Nano. 2008;2(3):463-470.

21. Jung I, Dikin DA, Piner RD, Ruoff RS. Tunable Electrical Conductivity of Individual Graphene Oxide Sheets Reduced at "Low" Temperatures. Nano Letters. 2008;8(12):4283-4287.

22. Jin M, Jeong HK, Kim TH, So KP, Cui Y, Yu WJ, et al. Synthesis and systematic characterization of functionalized graphene sheets generated by thermal exfoliation at low temperature. Journal of Physics D: Applied Physics. 2010;43(27):275402.

23. Pei S, Cheng HM. The reduction of graphene oxide. Carbon. 2012;50(9):3210-3228.

24. Mural PKS, Sharma M, Madras G, Bose S. A critical review on in situ reduction of graphene oxide during preparation of conducting polymeric nanocomposites. RSC Advances. 2015;5(41):32078-32087.

25. Aladekomo JB, Bragg RH. Structural transformations induced in graphite by grinding: Analysis of $002 \mathrm{X}$-ray diffraction line profiles. Carbon. 1990;28(6):897-906.

26. Scherrer P. Bestimmung der Grösse und der inneren Struktur von Kolloidteilchen mittels Röntgenstrahlen. Nachrichten von der Gesellschaft der Wissenschaften zu Göttingen, MathematischPhysikalische Klasse. 1918;1918(2):98-100.

27. Sahoo SK, Mallik A. Simple, fast and cost-effective electrochemical synthesis of few layer graphene nanosheets. NANO. 2014;10(2):1550019.

28. Li ZQ, Lu CJ, Xia ZP, Zhou Y, Luo Z. X-ray diffraction patterns of graphite and turbostratic carbon. Carbon. 2007;45(8):1686-1695.

29. Ni Z, Wang Y, Yu T, Shen Z. Raman spectroscopy and imaging of graphene. Nano Research. 2008;1(4):273-291. 